\title{
The Importance of Increasing Health Literacy Content in Nursing Education
}

\section{Catherine E. Chung PhD RN CNE CCM ${ }^{1}$ Catherine A. Prato-Lefkowitz PhD RN CNE}

Abstract: As the United States healthcare system rapidly transforms, nursing education should incorporate increased health literacy content into its curricula to prepare nurses to be excellent patient educators.

Keywords: Health Literacy, Nursing Education, Affordable Care Act, Patient Education

\section{INTRODUCTION}

Nursing education in the United States is facing a number of critical changes. The healthcare system is rapidly and dramatically changing due to the implementation of The Patient Protection and Affordable Care Act, more commonly referred to the Affordable Care Act (ACA). Not only are millions of newly insured consumers now able to use preventive care, but acute care stays continue to be reduced, which increases patient acuity upon discharge and transition of care. Healthcare consumers must increasingly engage in their care planning and be able to participate in self-management of care. The U.S. population demographics are a challenge for nursing, as the Baby Boomers move into retirement age and chronic disease diagnoses apply to the majority of the aging population. Nursing education is tasked with preparing nurses who can critically think and develop a plan of care in which the consumer is central and can be taught necessary self-management skills. Nurses in any healthcare setting provide the majority of patient health education- nurses may be the only healthcare professional a consumer encounters. Since $88 \%$ of the U.S. public has been shown to have a lack of proficiency related to health literacy (Institute of Medicine Committee on Health Literacy, 2004) it is necessary for the nurse to assess and develop an individual education plan based on the patient's current knowledge, skills, and attitudes.

\section{Health Literacy}

With concerns about curricular overload in nursing education, why advocate for health literacy inclusion? Health literacy is a complex issue that requires individual assessment and intervention. Patients might be ashamed to admit they do not understand what is being taught, and research has described patients with lower health literacy as demonstrating lower levels of ability to manage their care compared to patients with higher health literacy (Institute of Medicine Roundtable on Health Literacy, 2011).

Health literacy, commonly defined by the Institute of Medicine (IOM) as the ability to obtain, understand, and act on healthcare information and instructions as an individual's capacity to obtain, process, and understand basic health information and services needed to make appropriate health decisions (Institute of Medicine Committee on Health Literacy, 2004). Not only does the definition go beyond monetary influences, language/culture, educational level, and ethnicity, but the ability to understand and use health information fluctuates depending upon one's emotional state as well (Shaw, Huebner, Armin, Orzech, \& Vivian, 2009). Less like a static scale, health literacy is better compared with a continuously fluctuating measure such as blood pressure. Since health literacy abilities are constantly changing and incorporate many variables, health literacy status must be frequently assessed to facilitate the best outcomes of the healthcare consumer.

There are several health literacy tools that healthcare providers can use to assess a patient's health literacy level such as the Test of Functional Health Literacy in Adults (TOFHLA) and the Rapid Estimate of Adult Literacy in Medicine (REALM). Limited English Proficiency patients present additional barriers to understanding (Sentell, Zhang, Davis, Baker, \& Braun, 2014). Some barriers to tool use include: the tools may take a significant amount of time to complete, the tools may not give a complete picture of a patient's health literacy status, patients may feel stigmatized during/after completing the tools (Cutilli, 2005; Parker, Ratzan, \& Lurie, 2003). Individuals with low health literacy have a lack of understanding of preventive care including screening tests and procedures such as mammography, immunizations, influenza injections, or Human Immunodeficiency Virus (HIV) and Acquired Immune Deficiency Syndrome (AIDS) counseling and testing (Institute of Medicine Roundtable on Health Literacy,

${ }^{1}$ Corresponding Author: cchung@nu.edu 
American Research Journal of Nursing, Volume 1, Issue 1, 2015 ISSN 2379-2922

2011). More than 800 research studies have demonstrated medical material is written at a level higher than that of an average high school graduate is able to comprehend (Wolf, Gazmararian, \& Baker, 2005). All of these factors call for nurses to be able to assess health literacy and administer patient education appropriately.

Administering health education and self-management instruction at an appropriate level of health literacy improves health outcomes and has the potential to positively impact healthcare economics. The U.S. healthcare system spends about $\$ 106$ billion per year on problems encountered by individuals with low health literacy; future costs of low health literacy are estimated to be more than \$1.6 trillion (Vernon, Trujillo, Rosenbaum, \& DeBuono, 2007). Evidence has supported the relationship between low health literacy, increased medical costs, and hospital readmissions (Koh et al., 2012). In a large literacy study in the United States, 12 researchers found that $44 \%$ of older adults (those 65 and older) scored in the lowest reading level (Kirsch, 1993). Among older adults 29\% were below basic level and another 30\% were at basic level (Hanoch \& Rice, 2011). This equates to over $80 \%$ of patients aged 60 years or older exhibiting inadequate health literacy. The result is that the vast majority of our senior citizens don't correctly read and interpret the instructions on medication bottles or follow-up care instructions (Cutilli, 2007).

Commonly, readmissions are due to a consumer's misunderstanding of medication use, which could be curtailed with education specific to the consumer's health literacy status (Wolf, et al., 2005). Healthcare providers should understand they will be interacting with patients who have low health literacy and that these patients may require alternative methods to receive needed information (Osborn, Cavanaugh, \& Kripalani, 2010; Speros, 2009). Providers can increase patient understanding by using a variety of teaching methods including pictures and visual aids, avoiding medical terminology, and avoiding abbreviations for medical terms, actively listening, asking for clarification of confused patient looks, and using the "teach-back" techniques (Osborn, et al., 2010). Not only will the individual have improved understanding and satisfaction with a healthcare encounter characterized by health literate communications, but healthcare economics will be positively affected as well.

\section{Why Nursing Education?}

The Essentials of Baccalaureate Education Nursing for Professional Nursing Practice identifies health literacy as an important concept under Essential VII (American Association of Colleges of Nursing (AACN), 2008; Smith \& Zsohar, 2011). Health literacy has been increasingly addressed as a public health issue, in the ACA, in the Plain Writing act of 2010, in Healthy People 2020, and by the Robert Wood Johnson Foundation related to developing a culture of health. The American Association of Colleges of Nursing (AACN) revised the professional standards document that provides a framework of essential concepts for baccalaureate nursing education (AACN, 2008). The AACN recommends that baccalaureate nursing curricula include emphasis on social justice and committing to the elimination of health care disparities in vulnerable populations. Assessing patients' health literacy level is an integral component of the commitment to social justice. The professional standards document further emphasizes that nursing schools need to integrate teaching strategies into their curricula to help undergraduate students learn about how to assess individual health literacy levels.

Health care provider awareness of the impact of limited health literacy on patients and the health care system is limited (Jukkala, Deupree, \& Graham, 2009). The literature supports the case that many nurses and other healthcare professionals have not been adequately trained in assessing and interacting appropriately with patients having lower health literacy levels (DeSilets \& Dickerson, 2009; Speros, 2009). Patient teaching is a core nursing responsibility (Baur, 2011). National nursing organizations such as IOM, Healthy People, and The Joint Commission have called for integration of health literacy concepts in nursing curricula (Smith \& Zsohar, 2011). Yet, nursing education lags behind, and does not address the competency of health literacy within undergraduate nursing programs. Few nursing schools have integrated health literacy education into their curriculum (Ku, Sheu, \& Kuo, 2007). There are varying definitions of health literacy, so there is little evidence to support effective strategies by nursing faculty to improve health information literacy of nursing students (Ku, et al., 2007). As a result, there is no standard health literacy content included in undergraduate nursing education (Sand-Jecklin, Murray, Summers, \& Watson, 2010). The literature reveals a gap in health literacy education and the effectiveness in changing nursing student knowledge, awareness, and application of health literacy principles in practice (Sand-Jecklin, et al., 2010). Recommendations for nursing education include incorporation of health literacy assessment into all patient assessment activities to identify patients for whom health literacy is an issue. Health literacy assessment results have significant implications for nursing practice and nursing education, as well as for guiding future research as they identified recommendations that all nursing education programs should be incorporating health literacy content throughout their undergraduate and graduate curricula (Mareno \& Hart, 2014; Sand-Jecklin, et al., 2010). 


\section{American Research Journal of Nursing, Volume 1, Issue 1, 2015 ISSN 2379-2922}

Education regarding health literacy assessment and tools does not stop once nurses graduate. Health care agencies must recognize the need for nurses at the bedside to have competencies in health literacy and provide educational opportunities for nursing staff (DeSilets \& Dickerson, 2009). Health care is rapidly changing and new models of care continue to emerge. New nursing graduates are required to be competent in core areas of nursing care, including patient education, and must prioritize their care to ensure safety outcomes for their patients. In addition to having competency with their skills, new nursing graduates need to be able to identify patients at risk for not being able to understand and act on health information, communicate health information and instructions in a way that promotes patient understanding, and check for patient understanding (DeSilets \& Dickerson, 2009; Speros, 2009). This effective communication will reduce hospital readmission rates, decrease health care costs, and help close the gap between patient-nurse-provider communications. Nurse educators have a responsibility to incorporate health literacy assessment, appropriate patient education interventions, and evaluation of understanding into nursing curricula.

\section{REFERENCES}

[1] American Association of Colleges of Nursing (AACN). (2008). The essentials of baccalaureate education for professional nursing practice.

[2] Baur, C. (2011). Calling the nation to act: Implementing the national action plan to improve health literacy. Nursing Outlook, 59(2), 63-69. doi: 10.1016/j.outlook.2010.12.003

[3] S0029-6554(10)00479-3 [pii]

[4] Cutilli, C. C. (2005). Do your patients understand? Determining your patients' health literacy skills. Orthopaedic Nursing, 24(5), 372-377; quiz 378-379.

[5] Cutilli, C. C. (2007). Health literacy in geriatric patients: An integrative review of the literature. Orthopaedic Nursing, 26(1), 43-48.

[6] DeSilets, L. D., \& Dickerson, P. S. (2009). Filling gaps in knowledge: Educating nurses to provide appropriate patient materials. The Journal of Continuing Education in Nursing, 40(4), 148-149.

[7] Hanoch, Y., \& Rice, T. (2011). The economics of choice: lessons from the U.S. health-care market. Health Expectations, 14(1), 105-112. doi: 10.1111/j.1369-7625.2010.00646.x

[8] Institute of Medicine Committee on Health Literacy. (2004). Health literacy: A prescription to end confusion. doi: NBK216032 [bookaccession]

[9] Institute of Medicine Roundtable on Health Literacy. (2011). Promoting health literacy to encourage prevention and wellness: Workshop summary. Washington, D.C.: National Academies Press.

[10] Jukkala, A., Deupree, J. P., \& Graham, S. (2009). Knowledge of limited health literacy at an academic health center. Journal of Continuing Education in Nursing, 40(7), 298-304. doi: 10.3928/00220124-20090623-01

[11] Kirsch, I. S. (1993). Adult literacy in America : a first look at the results of the National Adult Literacy Survey. Washington, D.C.: Washington, D.C. : Office of Educational Research and Improvement, U.S. Dept. of Education.

[12] Koh, H. K., Berwick, D. M., Clancy, C. M., Baur, C., Brach, C., Harris, L. M., \& Zerhusen, E. G. (2012). New federal policy initiatives to boost health literacy can help the nation move beyond the cycle of costly 'crisis care'. Health Affairs, 31(2), 434-443.

[13] Ku, Y., Sheu, S., \& Kuo, S. (2007). Efficacy of integrating information literacy education into a women's health course on information literacy for RN-BSN students. Journal of Nursing Research (Taiwan Nurses Association), 15(1), 67-77.

[14] Mareno, N., \& Hart, P. L. (2014). Cultural competency among nurses with undergraduate and graduate degrees: Implications for nursing education. Nursing Education Perspectives, 35(2), 83-88.

[15] Osborn, C., Cavanaugh, K., \& Kripalani, S. (2010). Strategies to address low health literacy and numeracy in diabetes. Clinical Diabetes, 28(4), 171-175.

[16] Parker, R. M., Ratzan, S. C., \& Lurie, N. (2003). Health literacy: A policy challenge for advancing high-quality health care. Health Affairs, 22(4), 147-153.

[17] Sand-Jecklin, K., Murray, B., Summers, B., \& Watson, J. (2010). Educating nursing students about health literacy: From the classroom to the patient bedside. [Article]. Online Journal of Issues in Nursing, 15(3). doi: 10.3912/OJIN.Vol15No03PPT02

[18] Sentell, T., Zhang, W., Davis, J., Baker, K. K., \& Braun, K. L. (2014). The influence of community and individual health literacy on self-reported health status. Journal of General Internal Medicine, 29(2), 298-304. doi: http://dx.doi.org/10.1007/s11606-013-2638-3

[19] Shaw, S. J., Huebner, C., Armin, J., Orzech, K., \& Vivian, J. (2009). The role of culture in health literacy and chronic disease screening and management. Journal of Immigrant and Minority Health, 11(6), 460-467. doi: http://dx.doi.org/10.1007/s10903-008-9135-5 
American Research Journal of Nursing, Volume 1, Issue 1, 2015

ISSN 2379-2922

[20] Smith, J. A., \& Zsohar, H. (2011). Teaching health literacy in the undergraduate curriculum: Beyond traditional methods. Nursing Education Perspectives, 32(1), 48-50.

[21] Speros, C. I. (2009). More than words: Promoting health literacy in older adults. Online Journal of Issues in Nursing, 14(3), 12.

[22] Wolf, M. S., Gazmararian, J. A., \& Baker, D. W. (2005). Health literacy and functional health status among older adults. Archives of Internal Medicine, 165(17), 1946-1952. 